\title{
Lymphocytotoxic antibodies in systemic lupus erythematosus: their clinical significance
}

\author{
BARRY BRESNIHAN, ROBERT R. GRIGOR, AND GRAHAM R. V. HUGHES \\ From the Rheumatology Unit, Royal Postgraduate Medical School, Hammersmith Hospital, London W12
}

Cold-reactive lymphocytotoxic antibodies are present in the serum of most patients with systemic lupus erythematosus (SLE) (Mittal et al., 1970; Terasaki et al., 1970). They appear to be equally cytotoxic for autologous and heterologous lymphocytes (Stastny and Ziff, 1971). Studies of the nature of these antibodies showed that their cytotoxic effect is temperature-dependent and maximal at $15^{\circ} \mathrm{C}$, that their immunoglobulin class is IgM, and that they are equally reactive with $\mathrm{T}$ and $\mathrm{B}$ lymphocytes (Winfield et al., 1975a). Studies of the clinical significance of cold-reactive lymphocytotoxic antibodies in SLE have shown a consistent association with neuropsychiatric complications (Butler et al., 1972; Bluestein and Zvaifler, 1976; Bresnihan et al., 1977b). In other respects, however, clinical studies have been inconclusive, which may partly be related to the retrospective nature of most series. Previous studies have suggested an association between cold-reactive lymphocytotoxic antibodies and lymphopenia (Winfield et al., 1975b; Utsinger, 1976). A detailed prospective clinical analysis of SLE began at Hammersmith Hospital in 1973. In all, 50 patients have been investigated, and their clinical features have been described elsewhere (Grigor et al., 1978). This report relates the clinical features in these patients to the presence of lymphocytotoxic antibodies.

\section{Patients and methods}

Fifty successive patients with SLE, seen at Hammersmith Hospital between 1973 and 1977, were intensively investigated during at least one hospital admission and subsequently followed as outpatients. A strict study protocol had been designed which included a large number of serological and noninvasive investigative procedures (Grigor et al., 1978).

LYMPHOCYTOTOXIC ANTIBODY ASSAY

Serum was obtained at each hospital visit and stored in aliquots at $-20^{\circ} \mathrm{C}$ until the time of testing. The two-stage microdroplet dye exclusion cytotoxicity assay was used (Mittal et al., 1968). Target lymphocytes from at least 20 of a panel of 27 normal subjects were used to test each serum sample. All incubations $\stackrel{\mathscr{C}}{\mathscr{C}}$ were at $15^{\circ} \mathrm{C}$. Fresh rabbit serum was used as a $\frac{\dot{\omega}}{\omega}$ source of complement. The degree of cytotoxicity was assessed independently by two observers using phase-contrast microscopy and without knowledge $\vec{N}$ of which serum was being tested. Cytotoxicity was 음 expressed as an index which represented the mean percentage of lymphocytes killed by each serum. The cytotoxicity index ranged between 1 and 8: $1=$ $<20 \%$ lymphocytes killed (regarded as normal); $2=20-40 \%$ killed; $4=40-60 \%$ killed; $6=60-$ $80 \%$ killed; and $8=>80 \%$ killed. Each serum wit a score of 2 or greater resulted in at least $20 \%$ lymphocyte killing in 10 or more donor lymphocy suspensions.

\section{SEROLOGICAL METHODS}

Antibodies to DNA were measured by the Farr $\stackrel{\mathbb{Q}}{\complement}$ ammonium sulphate precipitation technique (Pincus $\vec{\overrightarrow{ }}$ et al., 1969). ${ }^{14} \mathrm{C}$-DNA was obtained from the 3 Radiochemical Centre, Amersham. C3 concentrations were measured by radial immunodiffusion in agar (Kohler et al., 1967).

Statistical significance was determined by Student's $t$ test for unpaired samples.

\section{Results}

\section{CLINICAL FEATURES}

In all, 336 serum samples, together with clinical, $\frac{D}{0}$ haematological, and serological information, were available from 49 of the patients. Of these, 235 sera $N$ $(70 \%)$ showed abnormal lymphocytotoxicity and $N$ sera from 40 patients $(80 \%)$ had lymphocytotoxic antibodies at some time during the course of their $\omega$ illness. The Table lists the major clinical manifestations of SLE. The mean $( \pm$ SD) of the maximum cytotoxicity indices observed for each patient who at ${ }_{\mathscr{Q}}$ some time showed a particular feature is compared ${ }^{+}$ to the mean of those who did not. Thus the mean 
Table Lymphocytotoxic antibodies and individual clinical features

\begin{tabular}{|c|c|c|c|c|}
\hline & \multirow{2}{*}{$\begin{array}{l}\text { No. of } \\
\text { patients }\end{array}$} & \multicolumn{2}{|c|}{ Cytotoxicity* } & \multirow{2}{*}{$\begin{array}{l}P \\
\text { value }\end{array}$} \\
\hline & & Involved & Uninvolved & \\
\hline $\begin{array}{l}\text { CNS } \\
\text { Cutaneous } \\
\text { Arthritis } \\
\text { Serositis } \\
\text { Renal }\end{array}$ & $\begin{array}{l}21 \\
39 \\
43 \\
28 \\
18\end{array}$ & $\begin{array}{l}5.4 \pm 2.1 \\
4.4 \pm 2.1 \\
4.1 \pm 2.2 \\
4.1 \pm 2.1 \\
3.9 \pm 1.9\end{array}$ & $\begin{array}{l}3.1 \pm 1.4 \\
2.3 \pm 1.0 \\
3.7 \pm 1.1 \\
4.0 \pm 2.1 \\
4.1 \pm 2.3\end{array}$ & $\begin{array}{l}0.001 \\
0.004 \\
\text { NS } \\
\text { NS } \\
\text { NS }\end{array}$ \\
\hline
\end{tabular}

* Results are expressed as the mean ( \pm SD) of the maximum cytotoxicity indices observed for each patient with and without individual clinical features.

maximum cytotoxicity index of the 21 patients who at some time developed evidence of CNS involvement was $5 \cdot 4 \pm 2 \cdot 1$, compared with $3 \cdot 1 \pm 1 \cdot 4$ in those patients who remained free of neuropsychiatric disease. This difference was statistically significant $(\mathbf{P}<0.001)$. Similarly, there was a significant difference $(P<0.004)$ between the mean cytotoxicity index of those who developed cutaneous manifestations $(4 \cdot 4 \pm 2 \cdot 1)$ and those who did not $(2 \cdot 3 \pm 1 \cdot 0)$. There was no statistical difference between the indices of those who had, or had not, other major manifestations.

There was considerable fluctuation in the degree of cytotoxicity in individual patients throughout the study. However, there was no association between the changes in lymphocytotoxicity and the appearance of disease exacerbations. Indeed, in some patients the maximum cytotoxicity coincided with periods of apparent remission. Furthermore, the degree of lymphocytotoxicity was not noticeably altered by corticosteroid therapy. This is shown in Fig. 1, which compares the mean cytotoxicity $( \pm S D)$ of sera obtained from groups of patients taking various doses of prednisone or none. The lymphocytotoxicity was similar in each group and there was a considerable degree of overlap.

\section{HAEMATOLOGICAL FEATURES}

It was possible to compare lymphocyte counts with the lymphocytotoxicity of 114 sera. This figure excludes sera obtained from patients receiving cytotoxic agents such as cyclophosphamide or azathioprine. The results are shown in Fig. 2. No association between lymphopenia and the degree of lymphocytotoxicity was seen. Thus the lymphocytotoxicity of sera obtained from patients with severe lymphopenia $\left(<750 / \mathrm{mm}^{3}\right)$ was not different from patients with either moderate lymphopenia $\left(750-1500 / \mathrm{mm}^{3}\right)$ or normal lymphocyte counts $\left(>1500 / \mathrm{mm}^{3}\right)$. Furthermore, there was no association between lymphocytotoxicity and anaemia, leucopenia, or thrombocytopenia.

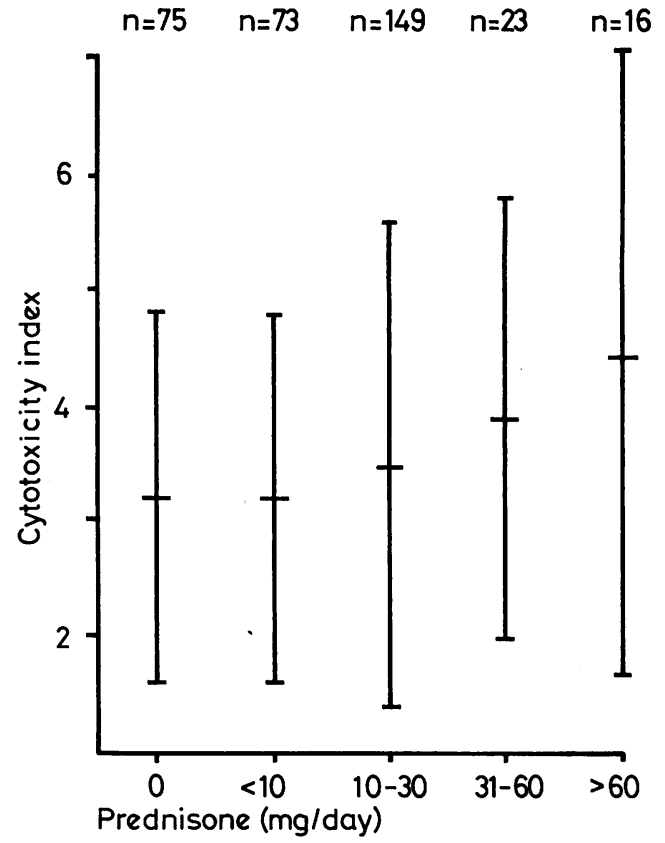

Fig. 1 Lymphocytotoxic antibodies and corticosteroid therapy. Mean ( $\pm S D$ ) lymphocytotoxicity of sera obtained from patients receiving various doses of prednisone.

\section{SEROLOGICAL FEATURES}

Comparison between lymphocytotoxicity and DNAbinding values was possible in 315 sera, and with $\mathrm{C} 3$ concentrations in 215 sera. Sera with normal DNAbinding values $(<30 \%)$ tended to be less cytotoxic than sera with raised DNA-binding values (Fig. 3), but the difference was not statistically significant. Furthermore, the mean lymphocytotoxicity of sera with DNA-binding values of $30-50 \%, 50-75 \%$, and $75-100 \%$ were almost identical. Similarly, the lymphocytotoxicity of sera with low C3 concentrations ( $<60 \%$ normal) and normal $\mathrm{C} 3$ concentrations showed an equivalent degree of overlap.

\section{Discussion}

Cold-reactive lymphocytotoxic antibodies are almost universally present in patients with SLE. Nevertheless, their role in pathogenesis remains unclear. The present study was undertaken to overcome the inherent problems of retrospective analysis so that further insight into the clinical relevance of lymphocytotoxic antibodies might be obtained. The most striking observation was that serum from patients with neuropsychiatric manifestations was more lymphocytotoxic than serum from patients without 


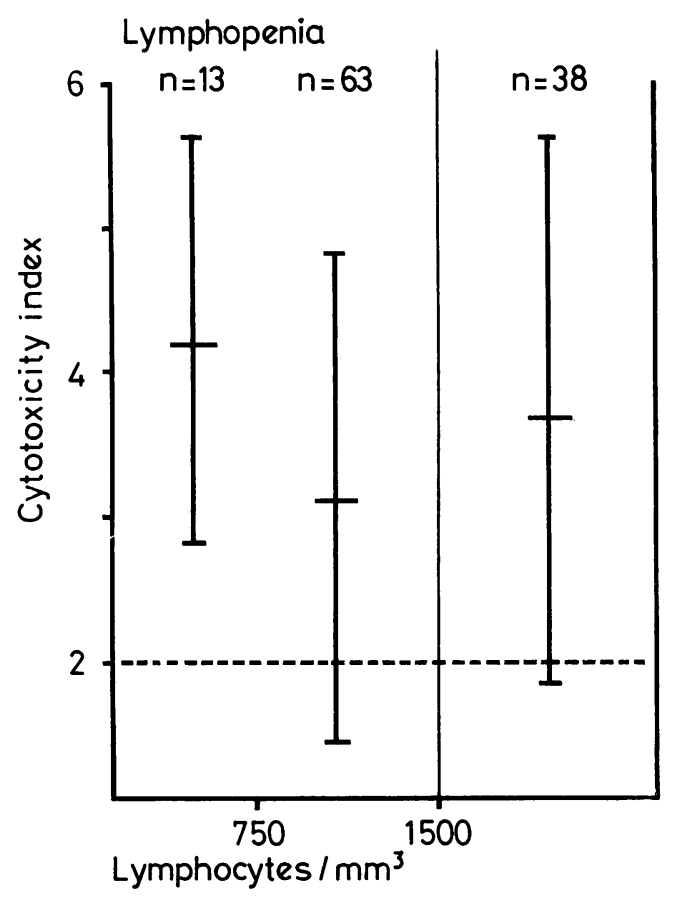

Fig. 2 Lymphocytotoxic antibodies and lymphocyte counts. Mean $( \pm S D)$ lymphocytotoxicity of sera shows no correlation with total lymphocyte counts determined at time of obtaining each serum sample.

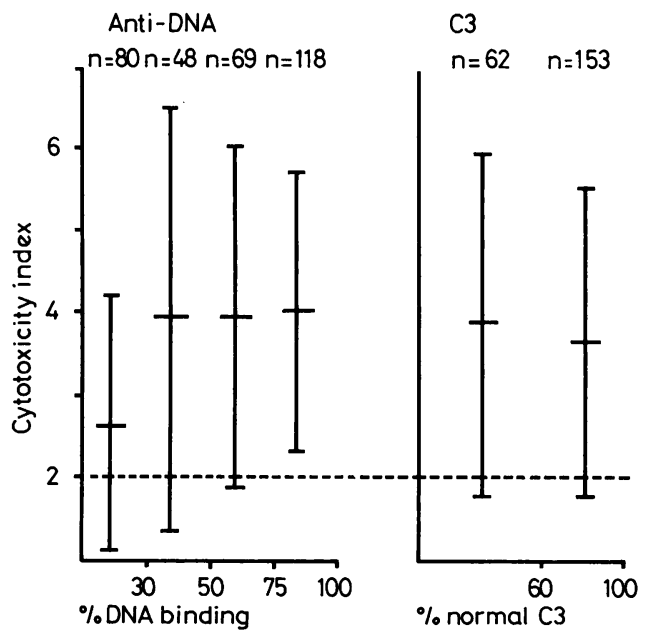

Fig. 3 Lymphocytotoxic antibodies, anti-DNA antibodies, and C3 levels.

these manifestations. This finding is in agreement with others (Butler et al., 1972; Bluestein and Zvaifler, 1976). These results, in association with the observation that lymphocytotoxic antibodies from patients who have neuropsychiatric symptoms crossreact with human brain (Bresnihan et al., 1977b), strongly suggest a possible pathogenic role in cerebral lupus. Our study suggests that of the other clinical manifestations only cutaneous lesions correlate with $\overrightarrow{\vec{s}}$ lymphocytotoxicity. Serological evidence of disease activity, as represented by DNA-binding values and등 C3 concentrations, does not appear to correlate with the lymphocytotoxicity of individual sera.

An association between lymphopenia and the presence of lymphocytotoxic antibodies has been ${ }^{\infty}$ previously reported (Winfield et al., 1975a; Utsinger, $\vec{\circ}$ 1976). This observation was not supported by our $\overrightarrow{-}$ study. It should be noted that our lymphocyto- $\omega$ toxicity assays were performed at $15^{\circ} \mathrm{C}$ using un-क्ष diluted serum samples. Assays performed under similar conditions by Winfield et al. (1975a) also failed to show an association with lymphopenia.c When they used undiluted serum samples they found.an association with lymphopenia only when assays $\vec{\overrightarrow{ }}$ were performed at $25^{\circ} \mathrm{C}$, suggesting the possibility that a distinct subpopulation of antilymphocyte ${ }^{\supset}$ antibodies may be cytotoxic at higher temperatures. $\vec{c}$ Previously, these authors had demonstrated that the predominant cold-reactive antilymphocyte antibody in SLE was maximally cytotoxic at $15^{\circ} \mathrm{C}$ and that the activity rapidly declined at higher temperatures $\overrightarrow{0}$ (Winfield et al., 1975b). Utsinger (1976) reported क्षे inverse linear correlation between serum cytotoxicicy measured at $15^{\circ} \mathrm{C}$ and peripheral blood lymphoce counts. However, this correlation was made with a relatively small number $(50)$ of matched samples and the degree of lymphopenia was modest (all greater? than $750 / \mathrm{mm}^{3}$ ). Others have observed associations between lymphocytotoxic antibodies and variouso other haematological disorders, such as haemolytic anaemia or thrombocytopenia, or both (Bluestein and Zvaifler, 1976), and leucopenia (Butler et al., 1972), but not specifically with lymphopenia. Again, these observations were not confirmed by us. Ito would indeed be surprising if an antibody whose 3 . cytotoxic capacity was so temperature-dependent ${ }_{0}$ could lead to substantial cell lysis at physiological temperatures. Clearly, other antibodies with differento physical requirements may yet be incriminated in the lymphopenia of SLE.

The in-vivo action of cold-reactive lymphocyto-n toxic antibodies on lymphocyte function remains. unclear. i spontaneously occurring thymocytotoxic $\sim$ antibody .tppears in New Zealand mice (Shirai and N Mellors, 1972), and it has been suggested that thiso antibody may result in altered lymphocyte function particularly impaired suppressor lymphocyte func- $\frac{\tau}{\varnothing}$ tion (Gelfand and Steinberg, 1973). Wernet and? Kunkel (1973) and Williams et al. (1973) have demonstrated an assortment of human antilympho- $\overrightarrow{\vec{D}}$ 
cyte antibodies that may modulate lymphocyte function, though these are apparently distinct from the characteristic IgM cold-reactive antibody.

The possibility that lymphocytotoxic antibodies cross-react with other tissue antigens and thereby mediate tissue injury has also been suggested. In this way reactivity with human brain antigens may result in cerebral manifestations (Bluestein and Zvaifler, 1976; Bresnihan et al., 1977b). In addition, crossreactivity with trophoblast-reactive lymphocytotoxic antibodies in SLE patients having spontaneous abortions suggested a possible role for these antibodies in the high spontaneous abortion rate (Bresnihan et al., 1977a). The demonstration of cross-reactivity with fetal erythrocytes but not adult erythrocytes suggested that cold-reactive lymphocytotoxic antibodies may share certain characteristics with cold agglutinins, such as specificity for $\mathrm{i}$ antigen (Goldberg et al., 1978). Possibly, therefore, lymphocytotoxicity is a feature common to many antibodies whose primary specificity is for antigens present on several different tissues. As suggested by our study, lymphocytotoxicity mediated by coldreactive antilymphocyte antibodies may never occur in vivo. The pathogenic effects of lymphocytotoxic antibodies may arise through reactions with other tissues.

We thank Miss Mary Oliver for her expert technical help. This work was supported by a grant from the Arthritis and Rheumatism Council and the Wellcome Trust.

\section{References}

Bluestein, H. G., and Zvaifler, N. J. (1976). Brainreactive lymphocytotoxic antibodies in the serum of patients with systemic lupus erythematosus. Journai of Clinical Investigation, 57, 509-516.

Bresnihan, B., Grigor, R. R., Oliver, M., Lewkonia, R. M., Hughes, G. R. V., Lovins, R. E., and Faulk, W. P. (1977a). Immunological mechanism for spontaneous abortion in systemic lupus erythematosus. Lancet 2, 1205-1207.

Bresnihan, B., Oliver, M., Grigor, R. R., and Hughes, G. R. V. (1977b). Brain reactivity of lymphocytotoxic antibodies in systemic lupus erythematosus with and without cerebral involvement. Clinical and Experimental Immunology, 30, 333-337.

Butler, W. T., Sharp, J. T., Rossen, R. D., Lidsky, M. D., Mittal, K., and Gard, D. A. (1972). Relationship of the clinical course of systemic lupus erythematosus to the presence of circulating lymphocytotoxic antibodies. Arthritis and Rheumatism, 15, 231-238.

Gelfand, M. C., and Steinberg, A. D. (1973). Mechanism of allograft rejection in New Zealand mice. I. Cell synergy and its age-dependent loss. Journal of Immunology, 110, 1652-1662.
Goldberg, L. S., Bresnihan, B., and Hughes, G. R. V. (1978). Lymphocytotoxic antibodies in systemic lupus erythematosus: evidence for reactivity with $\mathrm{i}$ antigen. Clinical and Experimental Immunology, 31, 443-447.

Grigor, R. R., Edmonds, J. P., Lewkonia, R., Bresnihan, B., and Hughes, G. R. V. (1978). Systemic lupus erythematosus. A prospective analysis. Annals of the Rheumatic Diseases, 37, 121-128.

Kohler, P. F., and Muller-Eberhard, H. J. (1967). Immunochemical quantitation of the third, fourth and fifth components of human complement: concentrations in the serum of healthy adults. Journal of Immunology, 99, 1211-1216.

Mittal, K. K., Mickey, M. R., Singal, D. P., and Terasaki, P. I. (1968). Serotyping for immunotransplantation. XVIII. Refinement of microdroplet lymphocyte cytotoxicity test. Transplantation, 6, 913-927.

Mittal, K. K., Rossen, R. D., Sharp, J. T., Lidsky, M. D., and Butler, W. T. (1970). Lymphocyte cytotoxic antibodies in systemic lupus erythematosus. Nature (London), 225, 1255-1256.

Pincus, T., Schur, P. H., Rose, J. A., Decker, J. L., and Talal, N. (1969). Measurement of serum DNA-binding activity in systemic lupus erythematosus. New England Journal of Medicine, 281, 701-705.

Shirai, T., and Mellors, R. C. (1972). Natural cytotoxic autoantibody against thymocytes in NZB mice. Clinical and Experimental Immunology, 12, 133-152.

Stastny, P., and Ziff, M. (1971). Antibodies against cell membrane constituents in systemic lupus erythematosus and related diseases. I. Cytotoxic effect of serum from patients with SLE for allogeneic and for autologous lymphocytes. Clinical and Experimental Immunology, 8, 543-550.

Terasaki, P. I., Mottironi, V. D., and Barnett, E. V.(1970). Cytotoxins in disease: autocytotoxins in lupus. New England Journal of Medicine, 283, 724-728.

Utsinger, P. D. (1976). Relationship of lymphocytotoxic antibodies to lymphopenia and parameters of disease activity in systemic lupus erythematosus. Journal of Rheumatology, 3, 175-185.

Wernet, P., and Kunkel, H. G. (1973). Antibodies to a specific surface antigen of $T$ cells in human sera inhibiting mixed leukocyte culture reactions. Journal of Experimental Medicine, 138, 1021-1026.

Williams, R.C., Jr., Lies, R. B., and Messner, R. P. (1973). Inhibition of mixed leukocyte culture responses by serum and $\gamma$-globulin fractions from certain patients with connective tissue disorders. Arthritis and Rheumatism, 16, 597-605.

Winfield, J. B., Winchester, R. J., and Kunkel, H. G. (1975a). Association of cold-reactive antilymphocyte antibodies with lymphopenia in systemic lupus erythematosus. Arthritis and Rheumatism, 18, 587-594.

Winfield, J. B., Winchester, R. J., Wernet, P., Fu, S. M., and Kunkel, H. G. (1975b). Nature of cold-reactive antibodies to lymphocyte surface determinants in systemic lupus erythematosus. Arthritis and Rheumatism, 18, 1-8. 